\title{
A PREVENÇÃO ÀS DROGAS COMO GARANTIA DO DIREITO À VIDA E À SAÚDE: UMA INTERFACE COM A EDUCAÇÃO
}

\author{
Luci Mara Bertoni \\ DulcinéIa DA Silva Adorni*
}

\begin{abstract}
RESUMO: Os apelos midiáticos do consumismo nos levam a fazer uma reflexão sobre o consumo de drogas e a sua prevenção. A falta de políticas públicas preventivas nos remete a pensar que o ser humano tem sido furtado do direito à vida e à saúde. O que se pretende aqui, sem usar jargões de campanhas de prevenção às drogas, mas concordando com a essência das palavras, é que prevenção também se ensina e a falha está em não compreendermos a importância de considerá-la em seus diferentes níveis.

Palavras-chave: Drogas. Prevenção. Direitos. Educação. Educação escolar.
\end{abstract}

DRUG PREVENTION AS A GUARANTEE OF THE RIGHT TO LIFE AND HEALTH: AN INTERFACE WITH EDUCATION

ABSTRACT: The media consumerism appeals inspired us to reflect on drug consumption and prevention. The lack of public preventive policies lead us to think that human beings have been deprived from their right to life and health. Without using the jargon of drug prevention campaigns, although we agree with the

* Doutora em Educação e professora-adjunta do Departamento de Filosofia e Ciências Humanas da Universidade Estadual do Sudoeste da Bahia (UESB).

E-mail:profaluci.mara@hotmail.com

** Mestre em Educação Escolar e professora do Departamento de Estudos Básicos e Instrumentais da UESB. E-mail: dulce.spba@hotmail.com 
A prevenção às drogas como garantia do direito à vida e à saúde...

essence of their words, we demand that prevention be also taught, since the fact that we do not understand the importance of considering it within its different levels.

Key words: Drugs. Prevention. Rights. Education. School education.

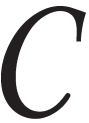

omumente, ouvimos dizer que o mundo contemporâneo está calcado nas premissas do "ter" em detrimento do "ser". Para se ter o bem de consumo tecnológico de última geração, o corpo escultural, o acesso a tudo aquilo que "enche os olhos dos outros" e, assim, ao nosso ego, vale quase tudo, ou, em alguns casos, vale mesmo tudo.

Silva (2008, p. 190) destaca três princípios ideológicos básicos que têm orientado nossos tempos: individualismo, relativismo e instrumentalismo.

1. $\mathrm{O}$ individualismo prega a busca do melhor tipo de vida a se usufruir. Entende-se como o melhor tipo de vida aquela que abrange o autodesenvolvimento, a auto-realização e auto-satisfação. De acordo com essa concepção, o indivíduo tem a "obrigação moral" de buscar sua felicidade em detrimento de qualquer outra obrigação com os demais.

2. Segundo o relativismo, todas as escolhas são igualmente importantes, pois não há um padrão de valor objetivo que me permita estabelecer uma hierarquia de condutas. Assim, qualquer ação que leva o indivíduo a atingir a auto-satisfação é válida e não pode ser questionada.

3. O instrumentalismo afirma que o valor de qualquer coisa fora de nós é apenas um valor instrumental, ou seja, o valor das coisas se resume no que elas podem fazer por nós.

Partindo destes pressupostos - individualismo, relativismo, instrumentalismo -, observamos que, na busca dessa autorrealização ou autossatisfação, o indivíduo pode se perder, apropriando-se de coisas que, num primeiro momento, trazem a sensação de "bem estar" ou de "felicidade", mas que, num curto decorrer de tempo, transformam-se justamente num veículo que leva à infelicidade, à angústia, à privação de sentido, de noção de certo e errado, entre outros prejuízos. Este "prejuízo" não se restringe ao indivíduo, mas pode afetar todos aqueles com ele envolvidos, direta ou emocionalmente. Para ter acesso a este "bem", o indivíduo muitas vezes desconsidera o outro, rouba, mata... 
Mas, que importância tem isso? Na nossa vivência cotidiana, privilegiamos o individualismo: a satisfação do indivíduo está acima do bemestar coletivo. Mais do que isso: para ser socialmente reconhecido, o sujeito precisa "ter". Aliás, não basta ter, precisa ter e mostrar que tem. Alie-se a esta concepção a noção de relativismo. Não há uma hierarquia de valores que permita ao sujeito pautar sua conduta. De quais valores, aliás, falamos? Numa sociedade que prioriza o "ter" em detrimento do "ser" fica difícil, quase impossível, falar em valores tais como respeito à vida (própria e do outro), solidariedade, responsabilidade (individual e social). O valor das coisas é instrumental, restringe-se ao que ela pode fazer pelo sujeito. Se a droga faz com que eu me sinta "feliz", por que não usá-la? Se a violência faz com que eu me sinta "forte", por que não praticá-la?

Neste emaranhado de ofertas de "felicidade" a qualquer preço, estamos cercados por uma busca exacerbada de superação das angústias, da ansiedade, de todo tipo de alteração de humor. Para isso, recorremos aos remédios. Aliás, "para tudo na vida, há um remédio", como afirmam nossos pais e avós, e, se procuramos, veremos que para todos os males há sempre uma forma medicamentosa de solução. Sem contar as formas cirúrgicas que oferecem a possibilidade de se ter um corpo escultural, pelo qual muita gente paga com a própria vida, só para citar um exemplo. A mídia dita a moda e a palavra de ordem é ter um corpo magro. Enquanto milhares de pessoas passam fome porque são privadas do acesso ao alimento, a indústria dos moderadores de apetite cresce assustadoramente e, com ela, uma gama de outros medicamentos para reparar os males que os primeiros provocam.

É diante deste quadro que tem crescido, também, a busca pelo uso de substâncias lícitas ou ilícitas que comumente chamamos de drogas. Este consumo vem aliado à busca de sensações de prazer, de poder, de pertença, e muitos de nós - pais, professores, familiares ou amigos - ficamos de mãos atadas diante de um crescimento tão avassalador que vem acompanhado de atos de violência. A violência tem tirado vidas tão próximas, tem nos tirado o direito de ir e vir sem medo de chegar, tem banalizado o direito à vida. Aliás, a vida não tem mais valor diante de uma pedra de crack ou de um tênis, por exemplo.

Nesta sociedade de consumo, quanto mais temos, mais vazios ficamos e menos valores preservamos. Um vazio que nos consome e nos 
A prevenção às drogas como garantia do direito à vida e à saúde...

faz querer mais, nos faz consumir mais, nos leva à busca de novas sensações e do desejo de, mesmo que por alguns instantes, experienciarmos um gosto de não sermos mais nós mesmos. Talvez sejam estas sensações que buscamos na experimentação ou utilização algum tipo de droga.

O que move uma pessoa em direção à droga está, na origem, muito perto do que levou o homem a se debruçar sobre o microscópio, ou a olhar através de um telescópio - o mesmo que impulsionou a tantos em direção ao sextante, aos mares bravios, às aventuras espaciais. Esse movimento de expansão, que nos empurra às grandes descobertas, afrontando o desafio do desconhecido, é parte do arsenal que nos fez humanos - reflexo do desejo de conhecer sempre mais, da ousadia de romper limites. Brota da sensação de desconforto de viver uma só vida, dentro de uma única pele. Algumas experiências podem romper essas limitações. Não muitas. Dentre elas: a arte, as paixões. E a droga. (Aratangy, 1998, p. 11)

Nesta busca desenfreada por novas sensações, também estão presentes os apelos do consumismo estampado nas diversas propagandas, que vendem a "felicidade", a "liberdade", a "sensualidade" e a "amizade" embutidas em seus produtos. Podemos perceber isto ao olharmos, atentamente, um comercial televisivo de cerveja. Esta última é considerada uma droga lícita e, embora haja recomendaçôes, obrigatoriamente presentes em todas as propagandas para moderação no seu uso ou para não dirigir após ingerir bebidas alcoólicas, ainda sofremos com as consequências desastrosas de quem dirigiu depois de beber "sem moderação". Diante de tais tragédias e de tantas outras que ouvimos cotidianamente, nos perguntamos se haveria alguma solução para os problemas relacionados ao uso/abuso de drogas lícitas ou ilícitas. Entendemos que, talvez, um dos caminhos para amenizar tal problemática esteja relacionado a se pensar estratégias de prevenção, visando assegurar o direito à vida e à saúde. Prevenção que, de acordo com Lapate (2001), deveria se iniciar na "hora zero" para se garantir que o embrião já não vivesse as consequências ocasionadas pelo uso/abuso de drogas por suas mães, por exemplo. Contudo, antes de adentrarmos na discussão sobre prevenção, valem as premissas orientadoras do que estamos entendendo por direitos. É neste contexto que gostaríamos de fazer uma reflexão sobre a ideia de direitos humanos. Afinal, o que são direitos humanos? Quem deve ser contemplado com eles? O agredido? 
$\mathrm{O}$ agressor? Ambos? De que tipo de agressão estamos falando? Agressão física a outrem? Agressão moral? Agressão a si mesmo? O sujeito que usa drogas, por exemplo, está desrespeitando os direitos humanos? Os dele próprio ou os dos outros?

Falar de direitos humanos não é tarefa fácil. Apesar de compor o vocabulário de grande parte da população, nem sempre as pessoas têm consciência do conteúdo sócio-político que os fundamenta. É comum o questionamento dos direitos humanos em situações extremas de violação, como nos casos de violência urbana, quando indivíduos são vítimas de assaltos, assassinatos, sequestros. Nestes casos, ficamos nos perguntando onde estão nossos direitos de ir e vir com segurança e tranquilidade, direito à vida, à propriedade etc. Mas, e no dia-a-dia? $\mathrm{O}$ direito à vida digna, ao estudo, ao trabalho, à saúde? Será que o usuário de drogas realmente está exercendo um direito ao "optar" pelo uso dessas substâncias? Afinal, o que são direitos humanos?

Direitos do homem, direitos naturais, direitos humanos, direitos fundamentais, valores superiores, garantias individuais, direitos concretos, liberdades públicas (...). Para alguns, trata-se de direitos inerentes à vida, à segurança individual, aos bens que preservam a humanidade. Para outros, é a expressão de valores superiores que se encarnam nos homens. Outros, ainda, entendem que são o produto da competência legislativa do Estado ao reconhecer direitos e estabelecer um equilíbrio na sociedade.

Uns entendem serem direitos inerentes à natureza humana, outros afirmam serem a expressão de uma conquista social através de um processo de luta pública. (Dornelles, 1997, p. 9)

Ao longo dos anos, diferentes declarações foram elaboradas definindo os direitos humanos. Como refere Dornelles (1997, p. 8), "diferentes declaraçôes, diferentes textos, diferentes momentos históricos (...) recheiam duzentos anos de história da humanidade". De acordo com o autor, todas elas apresentam um claro conteúdo político e representam não apenas ideais, mas "são o resultado de grandes lutas travadas pelos povos para se livrarem das correntes da opressão, da exploração, do preconceito e da violência”.

Para Dornelles (1997, p. 21), a concepção de direitos humanos pode ser dividida em três geraçôes: $1^{a}$ ) direitos individuais; $2^{a}$ ) direitos coletivos; $3^{\mathrm{a}}$ ) direitos dos povos ou direitos da solidariedade. A primeira geração caracteriza-se pela "expressão formal de necessidades 
A prevenção às drogas como garantia do direito à vida e à saúde...

individuais que requerem a abstenção do Estado para o seu pleno exercício", ou seja, "direitos civis e políticos, ou direitos individuais atribuídos a uma pretensa condição natural do indivíduo". Trata-se, portanto, de direitos naturais, inerentes à pessoa e anteriores à sociedade.

$\mathrm{Na}$ segunda geração, os direitos (sociais, econômicos e culturais) "exigem a ação positiva do poder estatal, criando condições institucionais para o seu efetivo exercício” (Dornelles, 1997, p. 30). Trata-se não só da elaboração dos direitos, mas também da criação de mecanismos que possibilitem sua viabilização.

Entre os direitos fundamentais da natureza social, econômica e cultural podemos apontar alguns exemplos: direito ao trabalho; direito à organização sindical, direito à previdência social em caso de velhice, invalidez, incapacidade para o trabalho, aposentadoria, doença etc.; direito à greve, direito à saúde, direito à educação gratuita; direito a uma remuneração que garanta condições dignas para o trabalhador e sua família (...). (Idem, ibid.)

Ainda na concepção do autor, a terceira geração dos direitos humanos, nascida das necessidades do pós-guerra (Segunda Guerra Mundial), refere-se aos "direitos a serem garantidos com o esforço conjunto do Estado, dos indivíduos, dos diferentes setores da sociedade e das diferentes naçôes". Destacam-se: o direito à paz; ao desenvolvimento e à autodeterminação dos povos; a um meio ambiente saudável e ecologicamente equilibrado; direito à utilização do patrimônio comum da humanidade.

Não podemos nos esquecer que o direito é inerente a todos os indivíduos. Nesse sentido, é preciso se pensar que todas as pessoas têm direitos, não só os mencionados anteriormente, mas tantos outros. Um deles é o direito à educação e, diríamos, à escolarização, que também tem sido negligenciado a tantas crianças, adolescentes e jovens, sobretudo os mais pobres. E a escola poderia ser um dos locais para se falar de prevenção, esta como garantia de outros direitos como a vida e a saúde. Tozzi e Bauer (1998, p. 109) afirmam que, de acordo com a Organização das Nações Unidas para a Educação, Ciência e Cultura (UNESCO), a escola "é o local mais adequado para o desenvolvimento de ações preventivas voltadas à melhoria da qualidade de vida”. No entanto, consideram que os professores se sentem despreparados para abordagens de alguns temas com seus alunos, principalmente no que 
se refere às drogas ou a comportamentos sexuais. Os autores destacam a escola como espaço de socialização do saber, com competência para mobilizar diferentes segmentos da sociedade, o que faz com que este espaço seja privilegiado para o desenvolvimento de ações preventivas.

Para a Federação Brasileira de Comunidades Terapêuticas (FEBRACT, 1998 , p. 44), a prevenção pode ser classificada em três níveis, a saber:

a) prevenção primária - tem por objetivo evitar a ocorrência do problema-alvo, isto é, diminuir a incidência. Previne o uso da droga antes que ele inicie;

b) prevenção secundária - ocorre quando já começa a surgir o consumo de drogas;

c) prevenção terciária - já existe a dependência de drogas, implica incentivar os usuários a procurar uma terapia adequada, incentivar o diálogo com a família, acreditar na recuperação, colaborar na reintegração social.

Embora todos os níveis aqui citados sejam considerados importantes, o que temos visto em algumas escolas, em estudo que vem sendo realizado no município de Vitória da Conquista (BA) (Bertoni, 2008), são ações mínimas de prevenção secundária ou terciária, isto é, que acontecem quando os problemas já foram identificados nas escolas. A realidade que nos circunda e que, infelizmente, não é privilégio deste município está marcada pela violência, pela ociosidade e pela falta de perspectivas entre crianças, adolescentes e jovens. E, cada vez mais, pais, filhos, alunos, professores e a sociedade em geral vêm sendo vítimas da violência advinda do comércio legal ou ilegal de drogas. Diante deste cenário, pouco tem sido falado de prevenção, até por medo de represálias que se possa sofrer por se tocar em tal assunto.

Em entrevistas para a pesquisa supracitada, alguns gestores parecem desconhecer ou desconsiderar que haja envolvimento de seus alunos com drogas, porque têm receio de falar do assunto. O que, também, não é novidade ao se tratar do referido tema.

Para nós, como dissemos anteriormente, a prevenção ao uso/abuso de drogas está relacionada às questôes fundamentais do direito à vida e à saúde que têm sido negligenciadas à maior parte da população. Há 
A prevenção às drogas como garantia do direito à vida e à saúde...

uma precarização cada vez mais crescente nos atendimentos públicos de saúde e de educação. Vivemos o paradoxo do corpo escultural, do consumismo exacerbado, da falta de educação, da proliferação de doenças, inclusive as que não mais apareciam entre a população. A necessidade de pertença e de aquisição de bens de consumo instiga os indivíduos, que valorizam a marca de um produto em detrimento de uma vida que se esvai, ou trocam uma vida por dinheiro que tilinta numa pedra de crack.

A negação dos direitos básicos do ser humano desencadeia uma série de prejuízos para os quais tentamos vislumbrar algumas soluçôes, mas que serão insolúveis enquanto não forem garantidas condições mínimas de sobrevivência. A raiz da problemática do aumento do consumo de drogas poderia ser atacada com ações efetivas de prevenção no âmbito escolar, se fosse garantido o direito à educação. Uma educação que contemplasse o crescimento e o desenvolvimento do indivíduo como pessoa que tem necessidades de alimento, de cuidados com a saúde, ou seja, indícios de uma vida digna.

Como consideramos, a temática do direito é árdua numa sociedade individualista e organizada de maneira a garantir que uns tenham mais direitos que os outros, dependendo das condiçôes econômicas e financeiras. Inúmeros são os apelos midiáticos para o consumo de bens e de serviços, inclusive para o uso/abuso de drogas lícitas e ilícitas. Mas o que também impera é a falta de políticas públicas de prevenção a este mesmo consumo.

Não se pode colocar a escola como a "tábua de salvação" para a resolução de todos os problemas, mas é possível tê-la como aliada nos processos de garantia da efetivação dos direitos.

Recebido em abril de 2010 e aprovado em agosto de 2010.

\section{Referências}

ARATANGY, L.R. O desafio da prevenção. In: AQuino, J.G. (Org.). Drogas na escola: alternativas teóricas e práticas. São Paulo: Summus, 1998. p. 9-17.

BERTONI, L.M. Campanhas educativas de prevenção às drogas: um mapeamento do ensino fundamental e médio em Vitória da Conquista. 
Vitória da Conquista: Universidade Estadual do Sudoeste da Bahia, 2008. (Projeto de pesquisa).

DORNELLES, J.R.W. O que são direitos humanos. São Paulo: Brasiliense, 1997.

FEDERAÇÃO BRASILEIRA DE COMUNIDADES TERAPEUTICAS (FEBRACT). Drogas: prevenção. In: Manual da FEBRACT. Campinas, 1998.

LAPATE, V. Hora zero: a independência das drogas antes que os problemas cheguem. São Paulo: Scortecci, 2001.

SILVA, A.B.B. Mentes perigosas: o psicopata mora ao lado. Rio de Janeiro: Objetiva, 2008.

TOZZI, D.; BAUER, J. Prevenção também se ensina? In: AQuino, J.G. (Org.). Drogas na escola: alternativas teóricas e práticas. São Paulo: Summus, 1998. p. 105-121. 